\title{
Philosophiques
}

\section{Index du volume IV}

Volume 4, numéro 2, octobre 1977

Philosophie et psychologie

URI : https://id.erudit.org/iderudit/014440ar

DOI : https://doi.org/10.7202/014440ar

Aller au sommaire du numéro

Éditeur(s)

Société de philosophie du Québec

ISSN

0316-2923 (imprimé)

1492-1391 (numérique)

Découvrir la revue

Citer ce document

(1977). Index du volume IV. Philosophiques, 4(2), 341-342.

https://doi.org/10.7202/014440ar

Ce document est protégé par la loi sur le droit d'auteur. L'utilisation des services d'Érudit (y compris la reproduction) est assujettie à sa politique d'utilisation que vous pouvez consulter en ligne.

https://apropos.erudit.org/fr/usagers/politique-dutilisation/
Cet article est diffusé et préservé par Érudit.

Érudit est un consortium interuniversitaire sans but lucratif composé de l'Université de Montréal, l'Université Laval et l'Université du Québec à Montréal. Il a pour mission la promotion et la valorisation de la recherche. https://www.erudit.org/fr/ 


\section{INDEX DU VOLUME IV}

1- Articles

W.H. DRAY, Les explications causales en bistoire

G. NOELTING, Le constructivisme piagétien et la théorie de l'équilibration illustrés par la construction de la notion de proportion

J.-C. BRIEF, Le constructivisme piagétien et les épistémologies traditionnelles....

M. GAGNON, Epistémologie génétique, science et philosopbie

R. PLANTE, Le pbénomène cognitif comme éco-système chez Piaget

C. STERLING, Les contestations contemporaines de la psychiatrie : de l'antipsychiatrie à la néo-psychiatrie

R. SAVOIE, La psychiatrie : une macbine à faire croire

M. LAFERRIÈRE, Les pièges de l'antipsychiatrie.

C. LÉVESQUE, L'inscription de la psychanalyse

F. PERALDI, La psychanalyse nord-américaine.

G. CHARRON, Inconscient social de la psychanalyse et points aveugles du psychanaliste

L. MONETTE, Le processus contre-transférentiel comme travail de deuil. 
J. N. KAUFMANN, Psychologie de la "conscience" et science $d u$ "bebavior"

M. SCHLEIFER, Behaviorisme et psychologie.

J. REINBOLD, Le behaviorisme et les psychologues sociaux

2- Étude critique

G. CHARRON, "Hobbes et Freud", par Jean Roy

3- Bulletin

Y. LAFRANCE, Les études platoniciennes : contribution canadienne (1970-1977)

4- Interventions

L'enseignement de la morale et la question de ses fondements

R. NADEAU, Présentation.

L. DUCHARME, Morale objective et loi naturelle.

R. NADEAU, L'enseignement de la morale dans une perspective relativiste.

E. JOOS, Le fondement de la morale et l'enseignement de la morale

L. MARCIL-LACOSTE, Le monopole confessionnaliste dans son rapport sur l'Éthique

B. PRUCHE, Discussion. 